\title{
De literatura, de vida. De literatura e de vida. Anotações de memória.
}

Um jantar há muitos anos, mais de vinte anos hão-de ser, a Branca cor de leite e muito composta, sentada a seu lado, à mesa do restaurante. Já nos tínhamos encontrado em assuntos de literatura, mas eu era de uma timidez sem nome e a figura dela intimidava. Havíamos sido apresentadas com tempo e sorrisos genuínos por Isabel Allegro de Magalhães, que não podia jantar connosco. Lembro-me então dessa noite, do meu nervosismo, as duas olhando-me, ela para mim ainda Maria Velho da Costa, ainda não Fátima, porque esse era o nome reservado para as amizades, e nós só nos conhecíamos dos livros, das palavras a partirem-se em versos curtos, cheias de sentidos outros, das situações fingidas mesmo que por vezes

mais verdadeiras, ias escrever, não, mais verdadeiras não, não vás pelo caminho fácil, isso éo mais óbvio, dizer que a literatura pode ser mais verdadeira que a vida. De facto, como eu escrevi uma vez, "a arte não é nada à vida”. Eu depois até me desdisse... Assim é quem escreve. Não, não há teoria, não se explica.

A Branca ficou umas linhas acima, ficou sem que eu a explicasse, a olhar-me em memória como nessa noite, os seus olhos de cadela Pug enormes, líquidos, cheia de rugas, pequena e com ar ameaçador. Mas doce, sempre, como a sua dona podia ser muitas vezes. Nessa noite, olhavam-me as duas, à nossa frente iscas à portuguesa e linguado grelhado, lembro-me muito bem, estas coisas de mantimento para o corpo não são menos importantes que as de mantimento para a alma - e não se esquecem facilmente, o corpo em habituamento bom e confortável. Nessa noite conversámos de literatura, eu levava um livro meu de poemas para lhe dar e os seus Maina Mendes e Casas Pardas para ela assinar e ela trazia uma prenda, Missa in Albis, esse livro que ela costumava dizer ter sido o seu mais custoso na escrita. E o seu preferido.

A partir daí, vimo-nos muitas vezes, jantei muitas vezes com ela e com a Isabel, ela já Fátima somente. Fátima para os amigos. Sempre que eu ia a Lisboa, encontrávamo-nos. Parávamos em sua casa, conversávamos um pouco, muitos cigarros, muitos. Depois, jantar. Jantámos em vários restaurantes, principalmente na Calçada da Ajuda, onde ela morava, nos últimos anos no Andorinhas, antes disso noutro restaurante que já fechou e cujo dono era o Sr. Vítor, a primeira pessoa a quem ela deu um exemplar de Irene, ou o Contrato Social quando recebeu o livro da editora. Generosidades grandes que tinha, lembranças para com os amigos. 
Cadernos de Literatura Comparada

De literatura, de vida. De literatura e de vida.

E falávamos de tudo; a Fátima era uma ouvinte maravilhosa, tinha um gesto muito seu de morder ligeiramente o polegar enquanto fitava a pessoa que estava à sua frente. Ou perscrutava, era isso, por vezes perscrutava. Sabia escutar, o que é raro. Falava de tudo, da infância, da escrita, das amizades, de livros, muito. E, assim como era generosa, também a encantavam pequeníssimos prazeres: uma prenda, uma surpresa. Ao lado das generosidades grandes, tinha pequenas alegrias de criança,

não é a inocência da criança igual à ignorância, mas a inocência como a dizia William Blake: "a inocência não organizada é uma impossibilidade, a inocência habita com a sabedoria, nunca com a ignorância”. E a tua escrita, Fátima, está aí também, no alto romantismo e no alto modernismo, nunca me pareceu que se enquistasse particularmente numa série de tiques do pós-moderno. Sim, sim, o pastiche, pois, o trazer para dentro do corpo do texto registos vários, citações. Claro que sim. Mas como dizia Blake... É dessa criança que falo.

Depois da Branca veio a Rosa, toda preta e da mesma raça. Adorava a Isabel e saltava-nos para o colo, mesmo quando já de meia-idade, redonda e arfante. Esse amor aos animais outros que não nós era muito da Fátima e está nos livros, está em Irene, vive com Myra. Conversávamos muito sobre cães e quando a Isabel teve a sua Lou (Andreas-Salomé, o que nos rimos!), a Fátima dava-lhe conselhos.

haverá alma? Não sabemos, Fátima, não sabemos nada. Onde estarás tu, se é que estás nalgum lugar? Junto com Rambô, o Rambo dessa história que tu dizias que era uma história para crianças grandes? Rambô, Rimbaud, o cão da dupla face, espécie de Jano, lutador e agressivo para muitos, poeta mas só para quem o merece. E se houver alma e um estado qualquer de dissonância desta vida mas em rasto dela, a Branca há-de estar aí também, e a Rosa. E a Lou, da Isabel. E a minha Lili Marlene. Onde estiveres.

Quando começou a pensar Myra, mostrou-me, no seu quarto, sobre uma mesa onde escrevia, os papéis, as canetas, os instrumentos necessários à passagem das palavras que surgem da mente e do coração. Uma passagem para um submundo terrível e maravilhoso. Foi isto no final de uma tarde, e há-de ter sido por volta de 2008. Passadas umas horas, ao jantar, disse assim: "Estão a chegar-me, as personagens". Muitos escritores falam deste fenómeno, mas sempre esta me pareceu uma frase antológica, por isso a citei muitas vezes. De onde lhe chegavam elas, as personagens? De que secreto lugar na mente? De mundos, decerto.

Uma vez, eu até descrevi esse processo como auditivo. A partir de certa altura é como se ouvisse vozes, eu disse isto. E só deixei ficar na minha Irene "a arte não é nada à vida" porque achei graça. Era para ser só o artigo, mas eles enganaram-se. O que eu tinha escrito de facto era "a arte não é nada a vida". A arte não é a vida, bem sabemos. Mas o parentesco, esse existe - e como. E eu: É como nos poemas. Amy Lowell disse uma vez "Não ouço uma voz, mas vozes pronunciadas. Mas sem som. 
Como se fossem pronunciadas dentro da minha cabeça, mas sem ninguém que as falasse. Subitamente, elas estão lá". Tu, em espanto: Como é que sabes tantas coisas de cor? Eu não sei nada de cor.

Mas sabia.

Sabia muito de Shakespeare, uma paixão comum; sabia passagens de cor (estás a ver?) das suas peças. Adorava Shakespeare, Camões, Virginia Woolf, Guimarães Rosa, Agustina, claro ("a Agustina devia ter tido o Prémio Camões antes de mim", dizia muitas vezes, nessa capacidade de admiração que só os grandes sabem ter).

Devo-lhe muito. Leu muitos livros meus de lápis na mão e era-me preciosa a sua opinião. Foi ela quem baptizou o meu único romance. "Ara, Ana Luísa, vai chamar-se Ara". E escreveu um texto lindíssimo para a badana do livro, que acabou por ficar na contracapa. Com um deslize... Ela havia-me ditado o texto ao telefone, com pontos, vírgulas, itálicos, etc.. E eu fui-o escrevendo, enquanto ela lia. "Agora, lê tudo", pedira ela no fim. Repeti tudo, com pontos, vírgulas, itálicos, etc., até chegar à frase de conclusão: "A brisa do arado sobre a ara", disse eu, estranhando um pouco aquela gentileza da imagem, tão pouco ao seu estilo. Mas ela deu o seu aval e eu mandei o texto ao editor. Quando lhe dei o livro, uns meses depois, demo-nos conta: era "deriva", não "brisa". Mas tínhamos as duas percebido mal a palavra: eu a que ela dissera, ela a que eu repetira. Só na edição seguinte a brisa se transformou no que devia ser: deriva.

Tantos que (tão bem) escreveram sobre ela: Manuel Gusmão, Isabel Allegro, Maria Irene Ramalho, também os mais jovens, entre os quais alguns dos que agora organizam este volume que a homenageia: Rui Miguel Mesquita, Ivana Schneider, Daniel Floquet... Eu citei-a muito, frases que são iluminações, roubei-a para epígrafes, "a revolução é o permanente retrocesso do sim ao seu princípio, deslumbrado"; "ah que eu possa saber de mim sabendo das coisas". Escrevi muito sobre Novas Cartas, esse livro que lhe era (acho que lhe terá sido sempre) ambivalente. E todavia a sua forma de estar foi o que se pode chamar feminista. Ela discordava às vezes, dizia que feminista, não era; outras vezes, concordava. E eu dizia feminista no mais puro sentido de defesa intransigente dos direitos humanos, tal como as figuras femininas que criou, autónomas e livres, desde Maina até Myra. Sim, mesmo Myra, na sua vulnerabilidade de menina imigrante, expulsada pela vida, mesmo Myra tem uma dignidade de

de humano. Nada mais há, a não ser isso: humano. Uma aprendizagem. "Revolucionar é aguentar até amar muito mais", eu sei o que escrevi. Humano.

Julgo que aquilo que a incomodava em Novas Cartas Portuguesas era o facto de o livro ter sido quase à nascença etiquetado como uma espécie de manifesto feminista, quando não como "a Bíblia do feminismo", ignorando-se que, para lá de acusar as formas sociais do patriarcado, questionando vários aspectos da vida nacional (a discriminação das mulheres, ou dos mais 
frágeis, a guerra colonial, a emigração), ele é, antes de mais, matéria literária. Uma enorme obra literária. Eu dizia-lhe que o livro é tão mais rico quanto diversas as formações das suas autoras: História e Filosofia, no caso de Maria Isabel Barreno, Românicas, no caso de Maria Teresa Horta, Germânicas, no caso dela, Fátima. No final, eu acho que a Fátima se reconciliou com ele (digo eu).

\section{Mais ou menos (diria ela).}

Não gostava de entrevistas, era avessa à exposição pública. A sua última entrevista, e esse é um orgulho que me fica, foi para um filme que Luísa Sequeira e Luísa Marinho fizeram sobre as três autoras de Novas Cartas - de facto, o filme não está ainda acabado, mas as entrevistas são únicas e preciosas. Eu era a entrevistadora. Já tínhamos feito longas entrevistas, separadas, a Maria Isabel Barreno (infelizmente também já não entre nós) e a Maria Teresa Horta. Tardes inteiras a falar com elas. A Fátima foi a última a ser entrevistada e resistiu bastante. Finalmente, anuiu. "Faço por amizade", disse-me ela, "e será a minha última entrevista". E foi, tanto quanto sei. Em 2013. Éramos sete criaturas na sua sala, nós as quatro, a Marinela Freitas, o operador de câmara e o seu ajudante; aliás, éramos oito, que a Rosa também contava, pois claro, e a sua excitação, desabituada que estava de ver tanta gente. A Fátima e eu fumávamos tanto que o operador de câmara tinha de parar de meia em meia hora, porque a sala parecia saída de uma noite londrina de final do século XIX. Fumo ou fog. No jantar desse dia falámos de Hannah Arendt e do filme que tinha acabado de estrear. A Fátima detestara o filme. "Não, o mal nunca é banal, o mal não pode nunca ser banalizado". E havia de voltar a isto várias vezes, falando de literatura, de vida. De literatura e de vida.

Por isso o desfecho de Myra. O cão a dizer à menina "Agarra-me bem (...) para eu bater com a espinha antes de ti". E as últimas palavras do livro, violentas e comoventes: "Myra tomou- o nos braços e atirou-se para trás, como um mergulhador equipado se atira de um barco de pesquisa submarina. Rambo ainda se debateu nos braços dela, na queda, mas eram já asas."

Não, o mal nunca é banal.

Chegámos a falar de traduzir os sonetos de uma das suas poetas de eleição, Elizabeth Barrett Browning. A Fátima era uma grande tradutora. No seu Irene, na sua Irene, figuração em papel da que escrevera "ao que vos parecer verso, chamai verso e ao resto chamai prosa", a magnífica passagem para a nossa língua da última fala de Próspero, o epílogo de A Tempestade. A tradução da Fátima, também magnífica. Salvador sozinho no palco:

Livrai-me das amarras.

Que o vosso sopro enfune as velas do meu querer -

- que era agradar. 


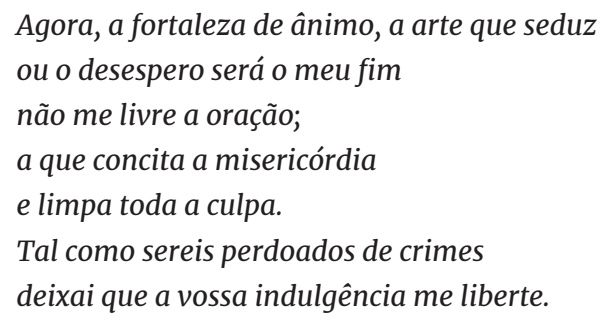

As velas do meu querer - que era agradar, assim fala Próspero/Shakespeare. Será isso, Fátima? Diz-se que Jorge Luis Borges declarou uma vez que os escritores, quando morrem, se transformam em livros. E acrescentava que talvez isso não fosse uma incarnação assim tão má...

Tenho muitas saudades tuas.

\section{Curtíssima nota:}

Quero agradecer a Daniel Floquet, Ivana Schneider, Elisabete Marques e Marta Correia, organizadores e organizadoras deste número dos Cadernos de Literatura Comparada, o convite que me fizeram para escrever um depoimento sobre Maria Velho da Costa. Quero ainda dizer o quanto este convite me honra.

Há quase dois anos, em Novembro de 2018, juntamente com Rui Miguel Mesquita e Lurdes Gonçalves, estes jovens investigadores organizaram o Colóquio Internacional Saber de mim sabendo das coisas, sob os auspícios do Instituto de Literatura Comparada Margarida Losa e em colaboração com o Teatro Nacional São João. Esse colóquio, que reuniu especialistas da obra de Maria Velho da Costa vindos de áreas diversas mas afins, como a literatura, o teatro, ou o cinema, foi uma bela homenagem aos 80 anos de vida desta escritora que nos deixou recentemente e cuja morte representou uma perda irreparável: a de uma grande pessoa e, para alguns de nós, de uma grande amiga; uma voz única no panorama literário, a voz de alguém que, como tão bem disse Isabel Allegro de Magalhães, habitou um estilo sempre inaugural mas sempre identificável. A morte de Maria Velho da Costa representa ainda a morte de uma fase áurea da literatura portuguesa, onde encontramos, em geração coeva e ao lado do seu, nomes como Nuno Bragança ou José Cardoso Pires - que ela tanto admirava.

O trabalho literário de Maria Velho da Costa contribuiu decisivamente para a renovação da literatura portuguesa nos séculos XX e XXI. Tal renovação deveu-se ao carácter inovador do seu experimentalismo linguístico, à transgressão formal acompanhada sempre do diálogo com a literatura e a cultura ocidentais, ao permanente inconformismo e ao tratamento de temáticas como a crítica à sociedade e à moralidade vigente ou a condição 
social, cívica, jurídica - humana. Maria Velho da Costa criou uma obra fundamental para cimentar a presença das mulheres na literatura portuguesa e, embora esta não fosse uma preocupação sua central, é inegável que temáticas ligadas à discriminação das mulheres ou à reivindicação de uma autonomia feminina ocupam os seus livros. Basta pensar em romances como Maina Mendes (1969) ou Casas Pardas (1977) ou em Novas Cartas Portuguesas (1972), de que foi co-autora, juntamente com Maria Isabel Barreno e Maria Teresa Horta. Nas formas múltiplas que exercitou na sua escrita, Maria Velho da Costa denunciou os tempos de horror quer do regime fascista de antes do 25 de abril quer da barbárie do capitalismo neo-liberal já mais próximo de nós - por isso mesmo exercitou também os gestos em direcção ao outro, um outro que, ao longo dos tempos e mais ainda nestes que correm e são nossos, incorpora a figura do desprotegido e do vulnerável - onde as mulheres se incluem, naturalmente.

A obra de Maria Velho da Costa explora territórios que extravasam o campo do literário e abalam noções de identidade ligadas ao sexo, ao género, à raça, à etnia, ou mesmo à espécie. Através dessas instâncias de questionamento, as fronteiras são denunciadas como matérias essencialmente construídas. Os seus romances ou os guiões que escreveu para cinema são muitas vezes moldados com a mesma matéria com que escreveu poesia como a de Corpo Verde (1979). E, sendo todos estudos poéticos sobre o poder, sobre a denúncia e o desencanto, são-no também sobre o amor ou sobre a compaixão, no sentido de sentir com, pedra de toque da comunicação, esteio fundacional dos princípios que nos estruturam, rente à coragem e à assunção do risco, diluindo as construídas demarcações entre literatura maior e literatura menor, adulto e infantil, humano e animal, privado e público - poético e político, em suma. Na última casa de Casas Pardas, quase a fechar-se o livro, diz Elvira, a criada: "Descasca hoje uma batata em meu nome sabendo que não lhe chamarei nunca tubérculo. Seja esse o teu primeiro exercício de igualdade entre os humanos". A morte, surgida como comum "destinação", igualmente "engelh[a] na emissão de radículas ávidas" o humilde e o poderoso, o raso e o sublime. Assim é a poesia dos seus textos.

Contribuir para homenagear alguém de quem tive o privilégio de ser amiga e cujo perfil literário se cruzou com esse de cidadania exemplar é uma honra para mim e o pequeno depoimento que aqui deixei tem carácter eminentemente pessoal. Uma forma muito simples de a recordar e lhe dizer obrigada. 